\title{
DECAY OF YELLOW BIRCH IN NOVA SCOTIA ${ }^{1}$ \\ BY M. A. STILLWELL 2

\author{
ABSTRACT
}

A study of the amount and types of decay in yellow birch, Betula lutea Michx. f., in Nova Scotia was undertaken in 1951 and 1952 in order to supply those concerned with information necessary for proper forest management of even-aged stands. A total of 374 trees was examined of which $35 \%$ contained some measure of decay. Volume of decay increased with increasing age. Approximately $50 \%$ of the trees contained decay at 120 to 130 years of age and $100 \%$ at 230 years of age. The loss in merchantable volume increased from a negligible amount at 60 years to about $10 \%$ at 240 years. No attempt was made to predict a rotational cut based on diameter. A pathological rotation age of 170 years is suggested for yellow birch in Nova Scotia. Ten wood-destroying fungi were found associated with rot in living trees, five in the butt and five in the trunk. Poria cocos (Schw.) Wulf. caused the most frequent butt rot and Fomes igniarius (L. ex Fr.) Gill. the most common trunk rot.

\section{INTRODUCTION}

Yellow birch has for years been the main hardwood species utilized in the Maritime Provinces. Summation of yearly data ${ }^{3}$ on hardwood lumber sawn in Nova Scotia from 1921 to 1950 is as follows:

Total volume of hardwood cut $517,728 \mathrm{M}$ f.b.m.

Total volume of yellow birch cut $352,546 \mathrm{M}$ f.b.m.

Approximately $68 \%$ of the hardwood cut during this period was yellow birch. Although birch throughout this region has suffered a serious setback from dieback, it still remains of prime economic importance.

During 1951 and 1952, a study of the nature of and loss from decay in yellow birch was carried out in Nova Scotia. It was felt that a knowledge of disease relationships and pathological rotation age would serve as an aid towards the correct management of the stands.

\section{LOCATION OF STUDY}

The location of the study plots is shown in Fig. 1.

In 1951, the trees were felled on three one-acre plots at Glenelg, Guysborough Co., and three one-half-acre plots at Glencoe, Inverness Co. In 1952, trees were felled on four one-acre plots on Crowdis Mountain, Victoria Co., two one-acre plots at Lake O'Law, Inverness Co., and 34 trees were felled in a partially cut-over area at Eden Lake, Guysborough Co.

\footnotetext{
${ }^{1}$ Contribution No. 174 from Forest Biology Division, Science Service, Department of Agriculture, Ottawa.

Agricultural Research Officer, Forest Biology Laboratory, Fredericton, New Brunswick. Biographical reference, Forestry Chronicle, Vol. 30, p. 292, September, 1954. Paper received for publication Novernber 18, 1954. ${ }^{8}$ Figures released by L. J. Pouliot of the Dominion Bureau of Statistics, Ottawa, in correspon-
dence.
} 


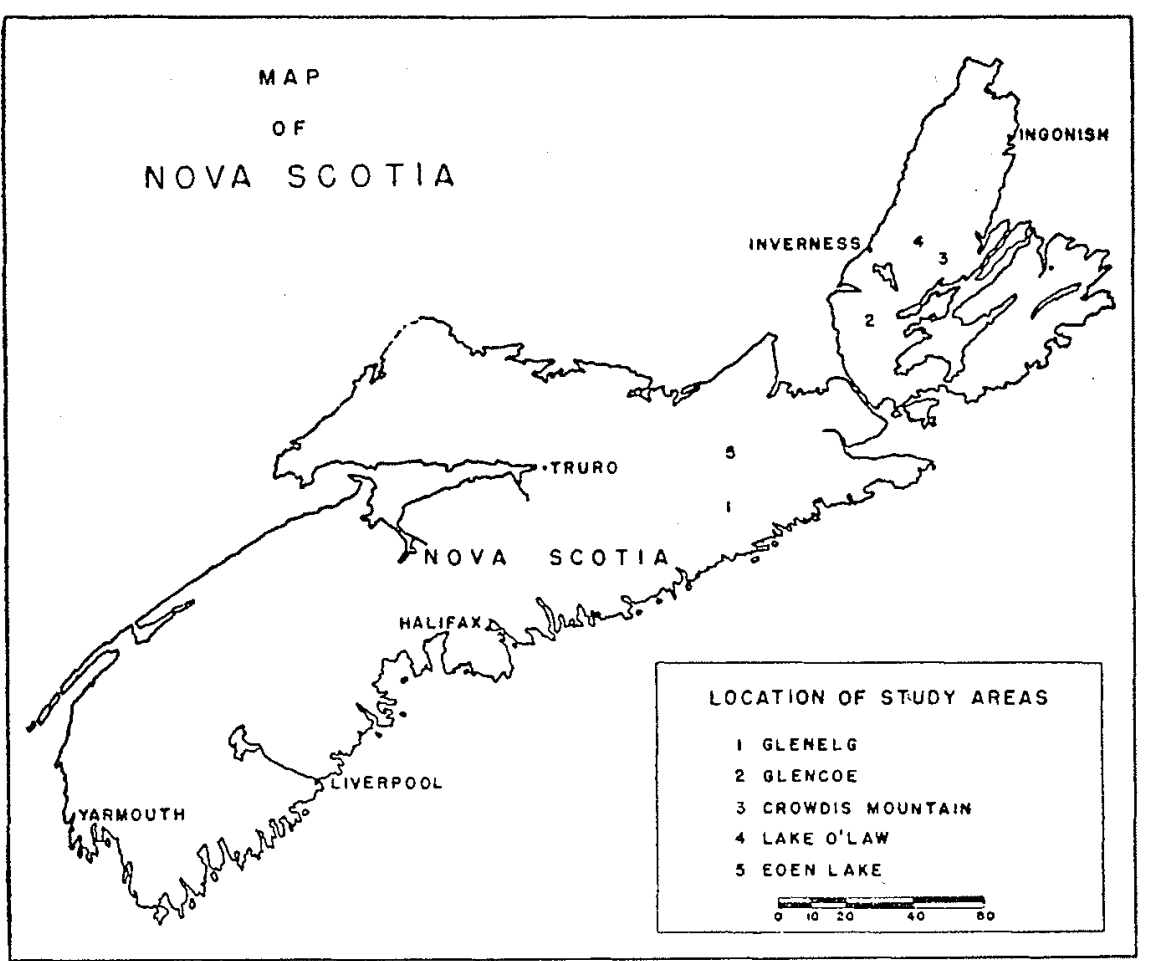

FIGURE 1. Map of Nova Scotia showing location of study areas.

\section{Method of StUdY}

All living trees in the plots with a D.B.H. o.b. greater than six inches were cut at a stump height of approximately one foot, except for a few trees where the size and shape of the butt made this impossible. A high percentage of the trees sampled had suffered dieback. The trees were sectioned into fourfoot bolts, scaled, and plotted on logarithmic tree measurement forms (SB239) ${ }^{4}$. If decay occurred at any section, it was scaled and plotted, the bolt being split longitudinally to determine the extent of the decay. The gross merchantable and decay volumes were obtained by planimetering the areas occupied by them on the tree measurement forms.

Discs were cut from bolts which contained decay, and later a culture was made from the decayed portion. All fungi thus isolated were submitted for identification to Dr. M. K. Nobles, Botany and Plant Pathology Division, Ottawa. A complete ring count was made at the stump of each tree and the stump age and tree age were considered the same.

- Modification of United States Dept. of Agr. Form 558A. 


\section{Decay in Relation to Diameter}

Diameter may be used to show a correlation with decay volume if the study area is small or as long as the site conditions remain the same. In any single area diameter may indicate tree vigor. A few of the more important conditions which might affect the vigor of the trees studied are mentioned in the following paragraph.

Height above sea level at which the five plots were situated varied from a few hundred feet to approximately a thousand feet. The difference in the temperature and amount of rainfall in the highlands of Cape Breton compared with the lower districts is shown by Putnam (1). According to Putnam, there is a great difference in the daily range of temperature, $26^{\circ} \mathrm{F}$. on the plateau as compared with $15^{\circ} \mathrm{F}$. at the sea-shore. Snowfall is much heavier in the highlands and remains longer on the ground. The humidity of the plateau is increased by the presence of fog and low-lying cloud banks which rest upon the summits while the lowlands remain clear. Frosts occur 18 days earlier than on the lowlands, and may be expected in all months of the year.

The plots on Crowdis Mountain are probably on the southern-most fringe of the Cape Breton Highlands, nevertheless the above conditions do occur. Farther north yellow birch is not so plentiful and the main tree species are balsam fir and spruce.

Table 1 shows that there is considerable range in the annual growth rate; that at Lake O'Law being $40 \%$ greater than at Eden Lake where growth was slowest. It might be of interest to point out that the two areas wih the greatest average yearly growth, Lake O'Law and Glencoe, were both irrigated by means of a brook which flowed through the plot area.

\section{TABLE I}

Relation Between Age and Incidence of Decay in Yellow Birch IN Nova Scotia

\begin{tabular}{ccrcc}
\hline \multirow{2}{*}{ Age Class } & \multirow{2}{*}{ Average Age } & \multirow{2}{*}{ No. of Trees } & \multicolumn{2}{c}{ Trees with Decay } \\
\cline { 4 - 5 } & & & Number & Percentage \\
\hline $41-60$ & 57 & 14 & 2 & 14.3 \\
$61-80$ & 75 & 109 & 16 & 14.7 \\
$81-100$ & 91 & 86 & 31 & 36.0 \\
$101-120$ & 110 & 82 & 34 & 41.5 \\
$121-140$ & 127 & 42 & 22 & 52.4 \\
$141-160$ & 147 & 18 & 8 & 44.4 \\
$161-180$ & 166 & 10 & 6 & 60.0 \\
$181-200$ & 191 & 6 & 4 & 66.7 \\
$201-220$ & 213 & 3 & 2 & 66.7 \\
$221-240$ & 230 & 2 & 2 & 100.0 \\
$241-260$ & 249 & 2 & 2 & 100.0 \\
\hline Totals & - & 374 & 129 & 34.5 \\
\hline
\end{tabular}


Because of the differences in the rate of growth, no attempt is made in this report to predict a rotational cut based on diameter. Table II and Fig. 2 show the relationship between diameter and decay volume, but no further comparison between these two is attempted and the following additional tables and graphs show the relationship existing between age and decay volume.

\section{Decay in Relation to Age}

Examination of Table III will show that there is an increase in the incidence of decay with increasing age. Approximately one-half of the trees contain decay at 120 to 130 years of age, and at 230 years all contain decay (column 4). Of the 374 trees examined, approximately one-third $(34.5 \%$, column 3) contained some measure of decay.

It is to be especially noted that the latter figure would probably have been higher if more trees had been used in the upper age classes (181 to 260 years). Because of decay at the stump, it was impossible to obtain the ages of 23 trees examined in the higher age classes and these are omitted from this table.

TABLE I

Relation Between Gross Volume and Decay Volume According to Diameter Classes

\begin{tabular}{|c|c|c|c|c|c|c|}
\hline $\begin{array}{c}\text { Diameter } \\
\text { Class } \\
\text { Mid- } \\
\text { points }\end{array}$ & $\begin{array}{l}\text { Number } \\
\text { of Trees }\end{array}$ & $\begin{array}{l}\text { Average } \\
\text { Diameter }\end{array}$ & $\begin{array}{c}\text { Average } \\
\text { Age }\end{array}$ & $\begin{array}{l}\text { Average } \\
\text { Gross } \\
\text { Volume } \\
\text { (Cu. Ft.) }\end{array}$ & $\begin{array}{l}\text { Average } \\
\text { Decay } \\
\text { Volume } \\
\text { (Cu. Ft.) }\end{array}$ & $\begin{array}{c}\text { Percent- } \\
\text { age of } \\
\text { Decay }\end{array}$ \\
\hline 6.0 & - & - & - & - & - & - \\
\hline 7.0 & 58 & 7.0 & 79 & 1.9 & - & - \\
\hline 8.0 & 52 & 8.1 & 81 & 3.8 & - & - \\
\hline 9.0 & 58 & 9.1 & 86 & 5.9 & - & - \\
\hline 10.0 & 39 & 10.1 & 98 & 8.0 & 0.1 & 1.2 \\
\hline 11.0 & 29 & 11.1 & 103 & 10.4 & 0.4 & 3.8 \\
\hline 12.0 & 30 & 12.1 & 104 & 12.0 & 0.6 & 5.0 \\
\hline 13.0 & 17 & 13.1 & 113 & 14.2 & 0.1 & 0.7 \\
\hline 14.0 & 18 & 14.0 & 125 & 19.9 & 0.5 & 2.5 \\
\hline 15.0 & 13 & 15.0 & 117 & 19.6 & 0.3 & 1.5 \\
\hline 16.0 & 13 & 16.0 & 128 & 19.8 & 0.6 & 3.0 \\
\hline 17.0 & 18 & 17.0 & 137 & 26.9 & 1.2 & 4.5 \\
\hline 18.0 & 8 & 18.1 & 145 & 31.2 & 2.2 & 7.1 \\
\hline 19.0 & 8 & 19.0 & 151 & 32.0 & 0.2 & 0.6 \\
\hline 20.0 & 6 & 20.1 & 156 & 32.0 & 2.3 & 7.2 \\
\hline 21.0 & 2 & 21.0 & 180 & 39.7 & 2.5 & 6.3 \\
\hline 22.0 & 1 & 22.0 & 216 & 50.3 & 1.0 & 2.0 \\
\hline 23.0 & 一 & - & - & - & - & - \\
\hline 24.0 & 3 & 24.0 & 199 & 60.8 & 3.3 & 5.4 \\
\hline 25.0 & - & - & - & - & - & - \\
\hline 26.0 & 1 & 26.0 & 109 & 53.4 & 12.3 & 23.0 \\
\hline Total & 374 & & & & & \\
\hline
\end{tabular}




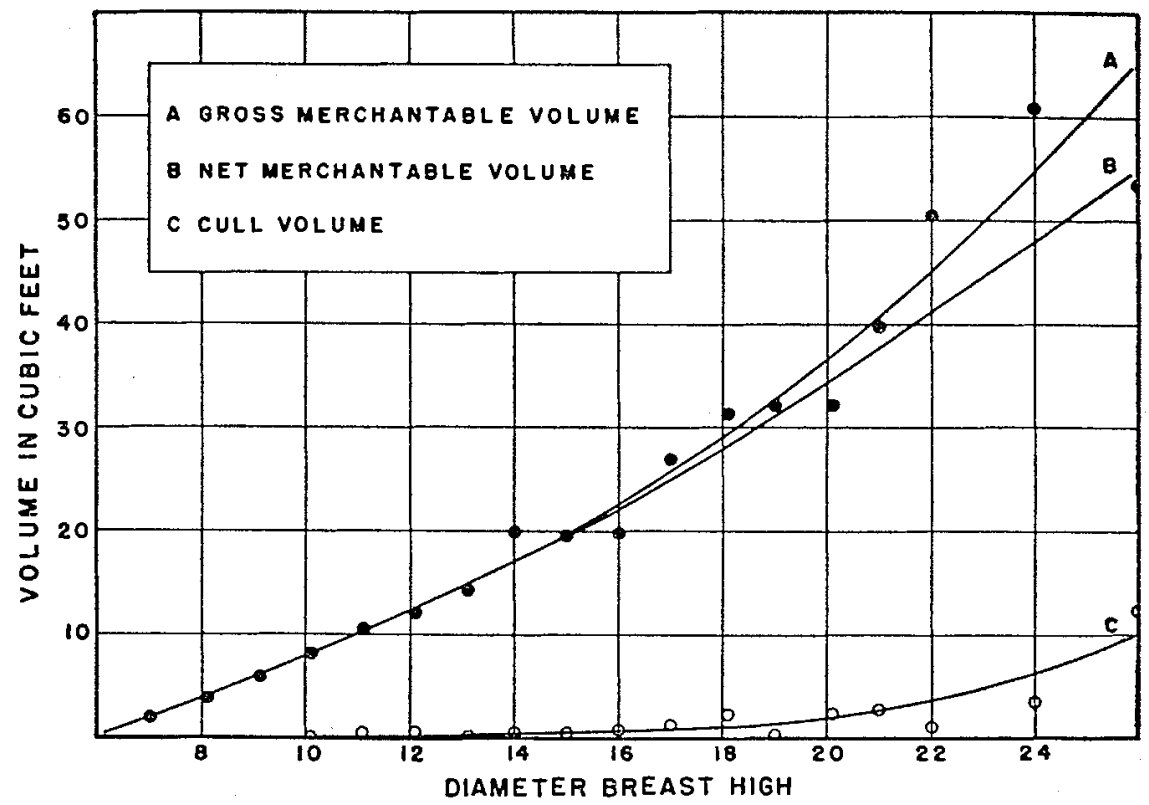

FIGURE 2. Relation between the average gross merchantable volume, average decay volume, average net volume, and diameter breast height.

\section{Volume Loss Due to Decay}

A study of Fig. 3, which is a graphical representation of data from Table III (columns 5 and 6 ) shows the relation that decay volume bears to gross volume for the average tree in each age class.

It will be seen that in Fig. 3, trees 60 years of age and under do not suffer any loss in volume from decay, and in trees 120 years of age it is still very small, representing approximately $3.0 \%$ of the gross volume. In trees 240 years of age decay volume is approximately $10.4 \%$ of the gross volume. A curve showing the net volume for an average tree in each age class is also given.

\section{Pathological Rotation of Yellow Birch in Nova Scotia}

A comparison of gross and net periodic increments is presented in Table IV and Fig. 4.

A study of Fig. 4 shows that the maximum net periodic increment occurs in trees from 130 to 150 years of age. However, the maximum gross periodic increment occurs in trees in the 150 to 170 -year age class and the net periodic increment in this age class is just slightly lower than in the preceding 130 to 150 year age class. 
TABLE III

Rezution Between Age, Incidence of Decay, Average Gross Volume, and Decay Volume in Yellow Birch in Nova Scotia

\begin{tabular}{|c|c|c|c|c|c|c|}
\hline \multirow[b]{2}{*}{ Age Class } & \multirow{2}{*}{$\begin{array}{c}\text { Average } \\
\text { Age }\end{array}$} & \multirow[t]{2}{*}{$\begin{array}{l}\text { (2) } \\
\text { Number } \\
\text { of Trees }\end{array}$} & \multicolumn{2}{|c|}{$\begin{array}{c}\text { (3) } \\
\text { Trees with Decay }\end{array}$} & \multirow[t]{2}{*}{$\begin{array}{c}\text { (5) } \\
\text { Average } \\
\text { Gross } \\
\text { Volume } \\
\text { (Cu. Ft.) }\end{array}$} & \multirow[t]{2}{*}{$\begin{array}{c}\text { (6) } \\
\text { Average } \\
\text { Decay } \\
\text { Volume } \\
\text { (Cu. Ft.) }\end{array}$} \\
\hline & & & Number & Percentage & & \\
\hline $41-60$ & 57 & 14 & 2 & 14.3 & 2.4 & 0.0 \\
\hline $61-80$ & 75 & 109 & 16 & 14.7 & 5.4 & 0.1 \\
\hline $81-100$ & 91 & 86 & 31 & 36.0 & 6.8 & 0.2 \\
\hline $101-120$ & 110 & 82 & 34 & 41.5 & 13.6 & 0.4 \\
\hline $121-140$ & 127 & 42 & 22 & 52.4 & 11.6 & 0.6 \\
\hline $141-160$ & 147 & 18 & 8 & 44.4 & 21.1 & 0.8 \\
\hline $161-180$ & 166 & 10 & 6 & 60.0 & 29.2 & 2.0 \\
\hline $181-200$ & 191 & 6 & 4 & 66.7 & 20.5 & 0.0 \\
\hline $201-220$ & 213 & 3 & 2 & 66.7 & 56.3 & 0.9 \\
\hline $221-240$ & 230 & 2 & 2 & 100.0 & 44.7 & 5.4 \\
\hline $241-260$ & 249 & 2 & 2 & 100.0 & 33.1 & 4.4 \\
\hline Total & & 374 & 129 & & & \\
\hline
\end{tabular}

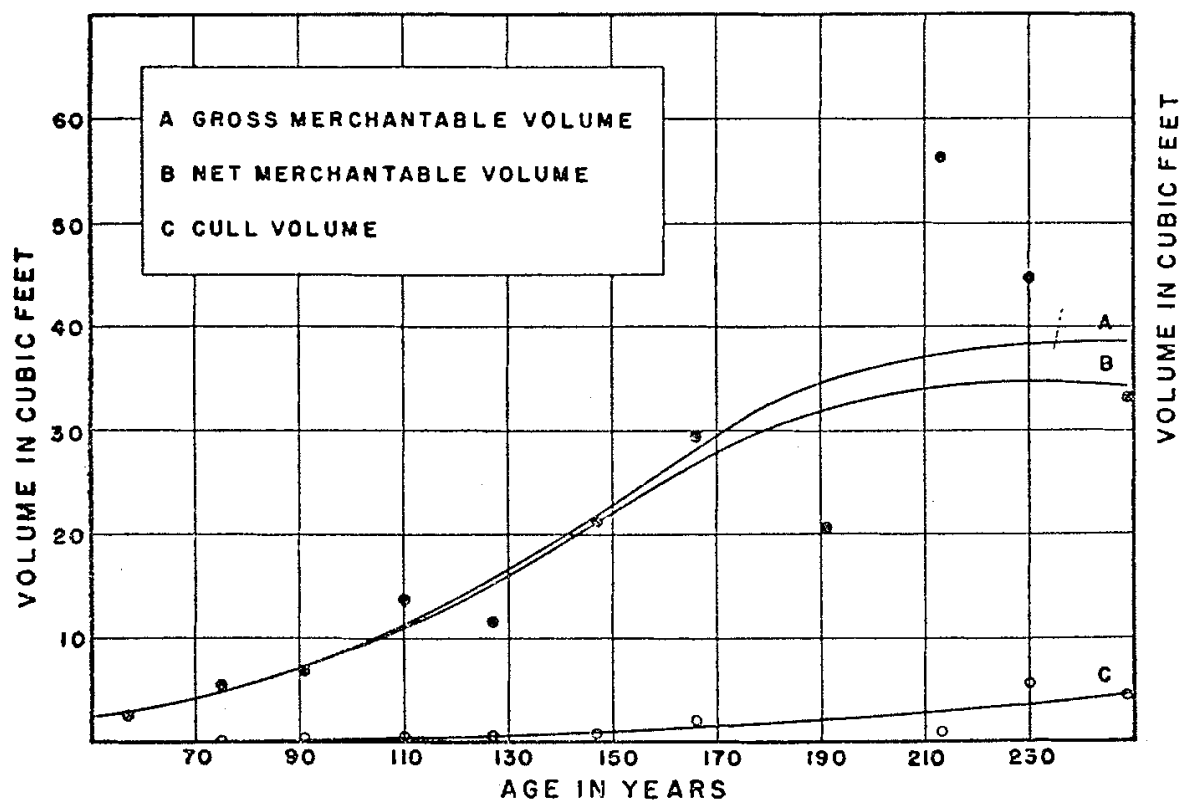

FIGURE 3. Average gross volumes, decay volumes, and net volumes in relation to age in yellow birch in Nova Scotia. 
It should be pointed out that the bulk of the trees examined were in the lower age classes (50 to 170 years of age) and trees in the upper age classes (170 to 300 years of age) were not plentiful, because of the heavy mortality caused by dieback. Since most of the trees had suffered dieback, a decrease in increment occurred in them. Had they grown under normal conditions, a higher net periodic increment would have been expected in the 150 to 170-age class. Therefore, the pathological rotation for yellow birch in Nova Scotia could be said to occur somewhere between 130 and 170 years, probably nearer the latter age.

TABLE IV

Relation Between Age, Decay Volume, and Net Periodic Increment IN Stands of Yellow Birch IN Nova Scotia

\begin{tabular}{|c|c|c|c|c|c|c|}
\hline \multicolumn{7}{|c|}{ Basis-374 trees (curved values) } \\
\hline$\underset{\psi}{\circ}$ & 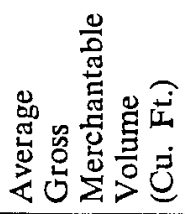 & 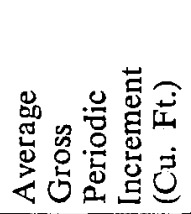 & 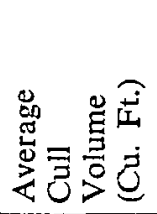 & 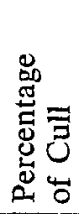 & 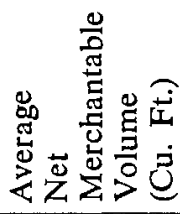 & 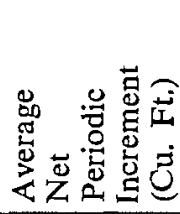 \\
\hline 50 & 2.4 & - & - & - & 2.4 & - \\
\hline 70 & 4.3 & 1.9 & - & - & 4.3 & 1.9 \\
\hline 90 & 7.2 & 2.9 & 0.2 & 2.8 & 7.0 & 2.7 \\
\hline 110 & 11.4 & 4.2 & 0.5 & 4.4 & 10.9 & 3.9 \\
\hline 130 & 16.5 & 5.1 & 0.5 & 3.0 & 16.0 & 5.1 \\
\hline 150 & 22.8 & 6.3 & 0.8 & 3.5 & 22.0 & 6.0 \\
\hline 170 & 29.8 & 7.0 & 1.9 & 6.4 & 27.9 & 5.9 \\
\hline 190 & 34.5 & 4.7 & 2.6 & 7.5 & 31.9 & 4.0 \\
\hline 210 & 37.0 & 2.5 & 3.1 & 8.4 & 33.9 & 2.0 \\
\hline 230 & 38.2 & 1.2 & 3.6 & 9.4 & 34.6 & 0.7 \\
\hline 250 & 38.6 & 0.4 & 4.5 & 11.6 & 34.1 & -0.5 \\
\hline
\end{tabular}

TYPES OF DECAY

Trunk rots are responsible for the greater volume loss due to decay in yellow birch in Nova Scotia. Table $\mathrm{V}$ reveals that the trunk rots and butt rots bear a ratio of almost $4: 1(78.5 \%$ to $21.5 \%)$ to the total loss through decay even though the ratio of infections is less than $2: 1$ ( 87 trunk rots to 52 butt rots.)

\section{WOOD-DEsTroytNG FuNGI}

Table $\mathrm{V}$ lists five fungi associated with butt rots and five fungi associated with trunk rots and their frequency of occurrence.

Poria cocos (Schw.) Wulf., Armillaria mellea (Vahl ex Fr.) Quél., and Odontia bicolor (Alb. \& Schw. ex Fr.) Bres. is the order of frequency in which the butt rots caused by these fungi occurred up to 1952 . In 1952, Stillwell (2) 
TABLE V

Wood-Destroying Fungi and Their Frequency of Occurrence

\begin{tabular}{|c|c|c|c|c|c|}
\hline \multirow[b]{3}{*}{ Type of Decay } & \multicolumn{5}{|c|}{ Number of Infections } \\
\hline & \multicolumn{3}{|c|}{ 1951-1952 } & \multirow[b]{2}{*}{ 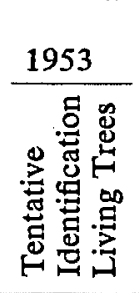 } & \multirow{2}{*}{$\begin{array}{l}1951- \\
1953 \\
\\
\text { 졍 }\end{array}$} \\
\hline & 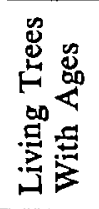 & 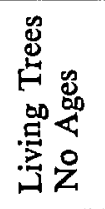 & 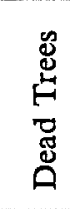 & & \\
\hline \multicolumn{6}{|l|}{ Butt Rots } \\
\hline $\begin{array}{l}\text { Armillaria mellea (Vabl ex } \\
\text { Fr.) Quél. }\end{array}$ & 1 & - & 4 & - & 5 \\
\hline $\begin{array}{l}\text { Corticium galactinum (Fr.) } \\
\text { Burt. }\end{array}$ & 1 & - & - & - & 1 \\
\hline $\begin{array}{l}\text { Odontia bicolor (Alb. \& } \\
\text { Schw. ex Fr.) Bres. }\end{array}$ & 3 & 1 & - & 2 & 6 \\
\hline Poria cocos (Schw.) Wulf. & 2 & 6 & 4 & 6 & 18 \\
\hline Ustulina vulgaris Tul. & 1 & - & - & - & 1 \\
\hline \multicolumn{6}{|l|}{ Trunk Rots } \\
\hline $\begin{array}{l}\text { Fomes igniarius (L. ex Fr.) } \\
\text { Gill. }\end{array}$ & 12 & - & - & - & 12 \\
\hline $\begin{array}{l}\text { Fomes igniarius var. } \\
\text { laevigatus (Fr.) Overh. }\end{array}$ & 1 & - & - & - & 1 \\
\hline Pholiota adiposa Fr. & 3 & - & - & - & 3 \\
\hline $\begin{array}{l}\text { Poria obliqua (Pers. ex Fr.) } \\
\text { Bres. }\end{array}$ & 6 & - & - & - & 6 \\
\hline $\begin{array}{l}\text { Stereum murraii (Berk. \& } \\
\text { Curt.) Burt }\end{array}$ & 2 & 一 & 一 & - & 2 \\
\hline
\end{tabular}

credited Armillaria mellea with causing the most common butt rot. This statement was based on cultures identified up to that time. Additional work on the identification of cultures does not support this statement.

A further survey on butt rots of yellow birch was carried out in 1953 in which samples were collected from different localities where logging operations were going on. The results of tentative identifications do not bear out the importance of the rot caused by Armillaria mellea. The tentative identifications of cultures made in 1953 further support the opinion that butt rot caused by Poria cocos ranks first in frequency of occurrence with Odontia bicolor second and Armillaria mellea third.

Fomes igniarius is shown to cause the most frequent trunk rot with that caused by Poria obliqua ranking second. 


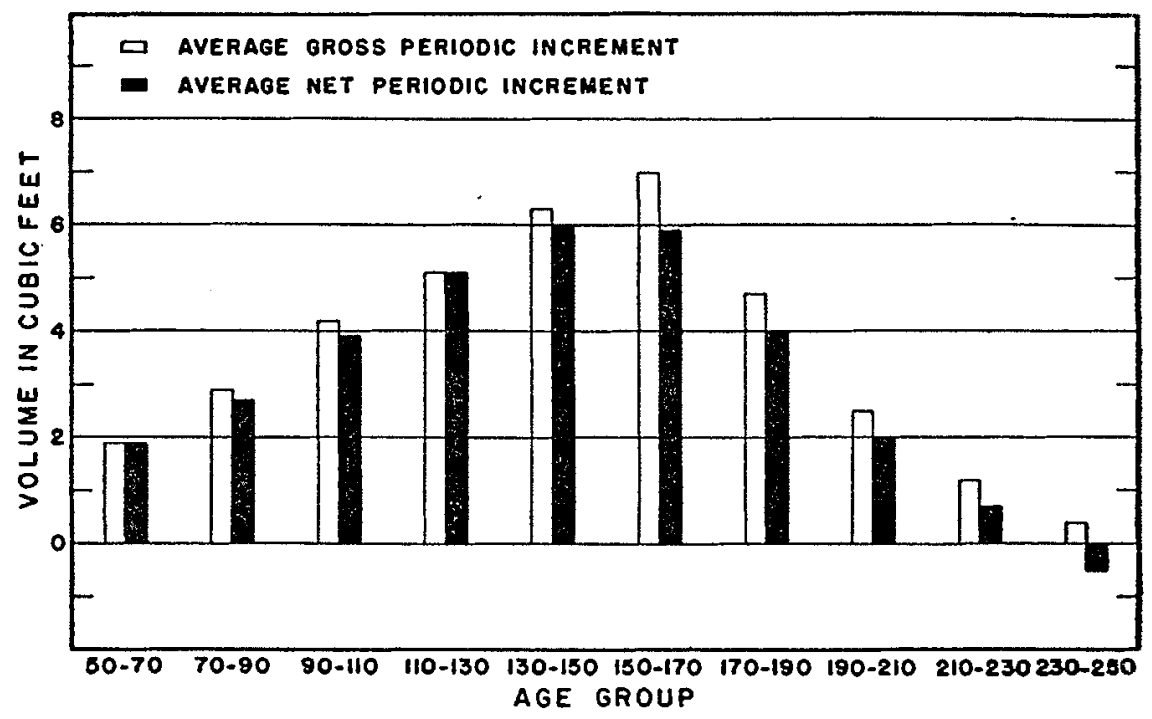

FIGURE 4. Comparison of gross and net periodic increments in cubic feet for Nova Scotia yellow birch of different age classes.

\section{Discussion}

This study was initiated in order to familiarize those concerned with the amount of decay and species of fungi that occur in yellow birch in Nova Scotia. The ages of the trees sampled varied from approximately 50 to 250 years, this including immature and mature trees. Very few overmature trees were sampled. Because of dieback, it would be difficult to find even a small stand of yellow birch which could be classified as overmature.

In many instances diameter is used as a basis for a cutting program, but because of the many factors which affect vigor of trees in different localities, little emphasis is placed on diameter in this study.

The rotation age for yellow birch in Nova Scotia, as indicated by the period of maximum gross periodic increment, occurs between 150 and 170 years. After deductions for decay (based on the actual cubic foot volume of decay), the maximum net periodic increment, which determines the pathological rotation age, occurs in trees from 130 to 150 years of age. During this period, the net periodic increment is only slightly higher than that in the 150 to 170 year age class. Since most of the trees experienced various stages of dieback which resulted in decreased increment, it is expected, had the trees grown normally, that the net periodic increment in this age class would have been as high as or possibly higher than that of the 130 to 150-year age class. Therefore, it is suggested that the pathological rotation for yellow birch in Nova Scotia be established at approximately 170 years. At present most of the cutting operations occur in stands where the average age of the trees approximates or 
is less than the suggested pathological rotation age. Hence, as a factor in determining the proper management of yellow birch stands, decay is not significant.

\section{ACKNOWLEDGEMENTS}

The author wishes to express his sincere appreciation to Dr. D. R. Redmond, Officer-in-Charge, and other members of the staff of the Forest Pathology Unit, Fredericton, for their interest and constructive criticisms and to Dr. M. K. Nobles and staff of the Botany and Plant Pathology Division, Science Service, Ottawa, for the identification of cultures made from decayed wood. Grateful acknowledgement for helpful information is made to District Foresters and their associates of the Nova Scotia Department of Lands and Forests, in whose territories this study was conducted. Co-operation from officials of the Canadian Lumber Company and the Oxford Paper Company on whose land parts of this study were carried out is gratefully acknowledged.

\section{Literature CrTed}

1. PUTNAM, D. F.-The climate of the Maritime Provinces. Can. Geog. Jour. 22:135-147. 1940.

2. STILL WELL, M. A.-Decay in yellow birch in the Maritime Provinces. Interim Report. Forest Pathology Unit, Fredericton, N.B. (mimeo.) 16 pp. 1952. 